\title{
AÇÃO AFIRMATIVA NO ENSINO SUPERIOR: ENTRE A EXCELÊNCIA E A JUSTIÇA RACIAL
}

\author{
SABRINA MOEHLECKE*
}

\begin{abstract}
RESUMO: $\mathrm{O}$ ensino superior brasileiro, nos debates atuais sobre sua reforma e expansão, tem diante de si o desfio de encontrar soluções que respondam à questão das desigualdades raciais no acesso às suas instituiçōes e na permanência nelas. Algumas universidades públicas já adotaram açōes nessa direção, ao estabelecerem cotas raciais ou sociais em seus processos seletivos. Contudo, essas experiências têm gerado significativas controvérsias. Neste artigo, com a intenção de explorar o debate sobre políticas de igualdade racial e o que motiva algumas de suas disputas, analisam-se dois de seus pontos mais polêmicos, a complexa relação de igualdade e a identificação racial que supõem, além de observar as maneiras com que foram implementadas em uma universidade norte-americana e as dificuldades enfrentadas nesse processo.
\end{abstract}

Palavras-chave: Ação afirmativa. Acesso ao ensino superior. Igualdade. Relações raciais. Experiência Estados Unidos.

\section{AfFirmative ACTION IN HIGHER EDUCATION: BETWEEN EXCELLENCE AND RACIAL JUSTICE}

ABSTRACT: The current debates around the Brazilian higher education are faced with the challenge of finding solutions to racial inequality in students' access and maintenance. Some public universities have already taken action and established racial or social quotas in their admission process. However, these experiences have provoked significant controversies. To explore the discussion on racialized politics and their arguments, this paper analyzes two of its most polemic issues, the complex equality concept and the racial identification it demands, and describes their impact on the United States universities.

Key words: Affirmative action. Access to higher education. Equality. Racial relationships. Experience in the United States.

Doutora em Educação pela Universidade de São Paulo (USP). E-mail: smoehlecke@yahoo.com

Educ. Soc., Campinas, vol. 25, n. 88, p. 757-776, Especial - Out. 2004 


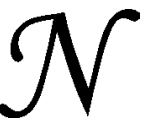

o início de 2004, cerca de 70 estudantes negros acorrentaramse em frente do prédio da reitoria da Universidade de São Paulo, exigindo a adoção de políticas de cotas e outras medidas que ampliassem o acesso ao ensino superior. $\mathrm{O}$ recurso às correntes foi de um grande simbolismo. Parte cotidiana da vida dos bisavôs de muitos desses estudantes nas senzalas brasileiras, hoje fixa seus descendentes a um espaço que até o momento ainda lhes é estranho, a universidade.

Se o ensino superior brasileiro continua aberto a poucos, isso se acentua drasticamente no caso dos alunos negros. Apesar de comporem 45\% dos brasileiros, a população preta e parda (de acordo com a classificação do IBGE) que conclui o ensino superior representa apenas $2 \%$ e $12 \%$ daquele total, respectivamente, comparado com $83 \%$ da população branca.

O sistema de ensino superior brasileiro, nos debates atuais sobre sua reforma e expansão, tem diante de si o desafio de encontrar soluções que respondam à questão das desigualdades raciais no acesso às suas instituiçôes e na permanência nelas. Algumas ações vêm sendo experimentadas, como os cursinhos pré-vestibulares comunitários para alunos negros e carentes, financiados pelo Ministério da Educação ou por universidades; a oferta de bolsas de estudo; a isenção das taxas de inscrição para o vestibular; e, inclusive, as chamadas políticas de cotas raciais ou sociais que, apesar das controvérsias, já são utilizadas por sete universidades públicas do país.

A discussão sobre políticas para a igualdade racial, contudo, não é recente. Um primeiro registro do que hoje chamamos de ação afirmativa data de 1968, quando o Ministério do Trabalho manifestou-se em favor da criação de uma lei que obrigasse empresas privadas a contratarem uma porcentagem de empregados negros. Mas tal lei não chegou a ser elaborada (Santos, 1999, p. 222). Foi somente nos anos de 1980, com a redemocratização do país, que o então deputado federal Abdias Nascimento formulou o primeiro projeto de lei propondo uma "ação compensatória” ao afro-brasileiro em diversas áreas da vida social como reparação pelos séculos de discriminação sofrida. O debate, restrito até então ao movimento negro e a alguns intelectuais, amplia-se a partir de meados dos anos de 1990. Em 1995, pela primeira vez, o presidente da República reconhece que o Brasil é sim um país racista e organiza um encontro, no ano seguinte, com o objetivo de pensar açóes que modifiquem essa situação. $\mathrm{O}$ momento simboliza uma mudança na maneira como o poder público vinha tratando a questão das relações 
raciais (Moehlecke, 2000). No entanto, seria preciso esperar mais oito anos para que o assunto entrasse na agenda política nacional, como ocorreu por meio do programa de combate ao racismo apresentado pelo governo federal na Conferência Internacional contra o Racismo, Xenofobia e Intolerância, realizado em Durban, na África do Sul, em 2001. Desde então, políticas de ação afirmativa direcionadas à população negra espalharam-se pelo país.

Os programas de ação afirmativa que começaram a vigorar em algumas universidades brasileiras surgiram articulados com movimentos sociais que exigiam maior igualdade e mecanismos mais eqüitativos no acesso a bens e serviços. Ligadas a sociedades democráticas pautadas no mérito individual e na igualdade de oportunidades como seus principais valores, essas ações propõem uma desigualdade de tratamento como forma de restituir uma igualdade que foi rompida ou que nunca existiu (Guimarães, 1997). Além do Brasil, já foram experimentadas em países como a Índia, após a independência, os Estados Unidos, no processo de extinção de leis segregacionistas, em países europeus, com relação aos imigrantes de ex-colônias e à população feminina.

Mas por que este continua um tema tão controverso e objeto de intensas disputas? Mais do que avaliar os argumentos contrários e favoráveis acerca das políticas de ação afirmativa, pretendo discutir dois de seus aspectos mais polêmicos, quais sejam, a complexa relação de igualdade e a conseqüente identificação racial que supõem tais políticas, por meio da análise do debate teórico a respeito e de como se concretizaram em uma experiência prática no âmbito do ensino superior.

\section{A igualdade que perturba a justiça do mundo moderno}

Existem dois significados clássicos de justiça, um que a identifica com a legalidade e outro que diz justa uma ação que respeita certa relação de igualdade. Em diversos ordenamentos sociais contemporâneos, sua conservação tem sido associada à observação de ambos os princípios de modo conjugado: "A alteração da igualdade é um desafio à legalidade constituída, assim como a não-observância das leis estabelecidas é uma ruptura do princípio de igualdade no qual a lei se inspira" (Bobbio, 1997, p. 15).

A igualdade, no debate político moderno, constitui-se em um dos valores fundamentais em que se inspiraram filosofias e ideologias. Desig- 
Ação afirmativa no ensino superior: entre a excelência e a justiça racial

nada positivamente como algo que se deseja, não possui, entretanto, um valor intrínseco. Consiste, antes, numa relação que se estabelece:

O que dá a essa relação um valor, o que faz dela uma meta humanamente desejável, é o fato de ser justa. (...) uma relação de igualdade é uma meta desejável na medida em que é considerada justa, onde por justa se entende que tal relação tem a ver, de algum modo, com uma ordem a instituir ou a restituir. (Bobbio, 1997, p. 15)

A justiça, em termos estritos, por estar no âmbito das questóes normativas, envolve constantemente desacordos morais, ao passo que a igualdade, em contrapartida, pode ser pensada em termos descritivos (Bobbio, 1993). Duas pessoas podem discutir e nunca chegar a um consenso sobre o que entendem por racismo ou discriminação racial e se os reprovam ou não, mas podem concordar sobre a existência ou não de uma relação específica de igualdade entre grupos raciais distintos.

Uma das máximas muito proclamadas no pensamento político ocidental é a de que "todos os homens são ou nascem iguais", mas o que atribui uma conotação positiva a esta enunciação não é a igualdade, "mas a extensão da igualdade a todos" (Bobbio, 1997, p. 23). Neste sentido,

dizer que dois entes são iguais sem nenhuma outra determinação nada significa na linguagem política; é preciso que se especifique com que entes estamos tratando e com relação a que são iguais, ou seja, é preciso responder a duas perguntas: a) igualdade entre quem?; e b) igualdade em quê? (Idem, ibid., p. 11-12)

Opondo-se aos mecanismos vigentes para a promoção e distribuição de status social, nos quais predominaram as distinçôes hereditárias e a divisão da sociedade por estamentos, as declarações de direito do mundo moderno igualaram os homens em seu momento de nascimento e estabeleceram o mérito e o esforço de cada um como medida para a repartição de bens, recursos e mobilidade social. Tal é o caráter universalista da concepção de igualdade civil, central ao pensamento iluminista: "O pressuposto ético da representação dos indivíduos considerados singularmente e não por grupos de interesse é o reconhecimento da igualdade natural dos homens. Cada homem conta por si mesmo e não como membro deste ou daquele grupo particular" (idem, ibid., p. 117). 
Contudo, das Luzes e da modernidade foram excluídos os índios, os escravos e os povos colonizados, que não compartilhavam da natureza humana dos chamados homens, e também as mulheres, supostamente incapazes, assim como as crianças, de fazerem uso da razão nos assuntos públicos. Declaraçôes de direito eram proclamadas ao mesmo tempo em que franceses e norte-americanos escravizavam grande parte da população negra mundial. A abolição da escravidão ocorreu nos Estados Unidos apenas em 1863 e a França manteve suas colônias até 1962.

$\mathrm{Na}$ segunda metade do século XX, a população negra liderou nos Estados Unidos o Movimento pelos Direitos Civis, exigindo o fim do sistema de segregação legal vigente no país e a inclusão efetiva dos exescravos na sociedade norte-americana. Novas políticas de igualdade, como a ação afirmativa, foram experimentadas como forma de garantir direitos a grupos historicamente excluídos de sua cidadania plena. Denunciaram que a igualdade abstrata não significou, necessariamente, a garantia de relaçóes justas.

A igualdade de oportunidades liberal traz como ideário diminuir a influência de circunstâncias sociais e de dotes naturais sobre a riqueza distribuída. No entanto, tem sido insuficiente para evitar que condiçōes adscritas, como a raça e o sexo, sirvam como critério de hierarquização social e de uma distribuição desigual de bens e serviços. John Rawls, filósofo político e autor do clássico Uma teoria da justiça, afirma, no contexto das tensões sociais decorrentes dos movimentos iniciados nos Estados Unidos na década de 1960, que tanto a liberdade civil das declarações modernas, com suas desigualdades sociais, quanto a igualdade de oportunidades, com as desigualdades naturais, são igualmente arbitrárias do ponto de vista moral. Propõe, então, uma política da diferença e a utilização da identificação racial como nova medida de igualdade. De acordo com Rawls,

(...) ninguém merece a maior capacidade natural que tem, nem um ponto de partida mais favorável na sociedade. Mas, é claro, isso não é motivo para ignorar essas distinções, muito menos para eliminá-las. Em vez disso, a estrutura básica [da sociedade] pode ser ordenada de modo que as contingências trabalhem para o bem dos menos favorecidos. Assim somos levados ao princípio da diferença se desejamos montar o sistema social de modo que ninguém ganhe ou perca devido ao seu lugar arbitrário na distribuição de dotes naturais ou à sua posição inicial na 
Ação afirmativa no ensino superior: entre a excelência e a justiça racial

sociedade sem dar ou receber benefícios compensatórios em troca. (Rawls, 2002, p. 108)

Para o autor, a distribuição natural de talentos ou a posição social que cada indivíduo ocupa não são justas nem injustas; o que as torna justas ou não são as maneiras pelas quais as instituições as utilizam.

Entendendo ambas as igualdades anteriores como injustas, Rawls propôe o que define como igualdade democrática, obtida por meio da combinação do princípio da igualdade de oportunidades com o princípio da diferença (idem, ibid., p. 79). Nascer com alguma deficiência física ou mental, por exemplo, não é uma questão de escolha individual; talentos naturais e circunstâncias sociais são ambos resultantes da sorte, o que está além da decisão de cada um: "Aqueles que nasceram com alguma deficiência não possuem uma igual oportunidade de adquirir benefícios sociais, e sua ausência de sucesso não tem nenhuma relação com suas escolhas ou esforços. Se estivermos genuinamente interessados em remover desigualdades não merecidas, então a visão dominante de igualdade de oportunidades é inadequada” (Kymlicka, 1996, p. 57).

Dialogando com as questóes de sua época, seu princípio da diferença tem vários pontos de aproximação com as políticas de ação afirmativa, ainda que não sejam a mesma coisa. Para Rawls, as desigualdades de nascimento, os dons naturais e as posições menos favorecidas advindas de gênero, raça, etnia são imerecidas e têm de ser compensadas de algum modo:

O princípio [da diferença] determina que a fim de tratar as pessoas igualitariamente, de proporcionar uma genuína igualdade de oportunidades, a sociedade deve dar mais atenção àqueles com menos dotes inatos e aos oriundos de posiçōes sociais menos favoráveis. A idéia é de reparar o desvio das contingências na direção da igualdade. (Ralws, 2002, p. 107)

Àqueles que consideram injusta a compensação por supostamente atentar contra a noção de mérito, Rawls questiona o quão meritórios são os dotes naturais ou as posições desfavoráveis socialmente. Serão resquícios de sociedades religiosas, nas quais os dons e o status social são distribuídos de acordo com a casta à qual pertencemos? Conclui, pois, que esta não é uma questão que envolve o mérito:

Talvez alguns pensarão que uma pessoa com maiores dons naturais mereça aquelas vantagens e o caráter superior que tornou possível seu de- 
senvolvimento. Porque é mais digno neste sentido, merece as maiores vantagens que puder alcançar com seus dons. Esta visão, entretanto, é certamente incorreta. Um dos pontos recorrentes de nossos juízos analisados até agora é que ninguém merece o seu lugar na distribuição dos dons naturais, mais do que mereça seu ponto de partida na sociedade. Afirmar que um homem merece o caráter superior que lhe permite esforçar-se para cultivar suas habilidades é igualmente problemático, pois seu caráter depende largamente de uma família privilegiada e de circunstâncias sociais, pelas quais não tem mérito algum. Não parece aplicar-se a noção de merecimento a tais casos. Dessa forma, o homem representativo mais privilegiado não pode dizer que o mereça e, portanto, que tenha direito a um esquema de cooperação no qual lhe seja permitido adquirir benefícios de modo que não contribuam ao bem-estar alheio. (Rawls, 1973)

Rawls distancia-se da tradição liberal ancorada na idéia de igualdade de oportunidades e de sua respectiva concepção de mérito, circunscrita a algumas situações sociais. Ao rediscutir o ideal meritocrático, ressalta suas limitações e ressignifica-o historicamente ao considerá-lo no âmbito dos usos e fins que a sociedade atribui às diferenças, inatas ou sociais. É sob esta perspectiva que concebe o princípio da diferença como algo intrínseco à estrutura da sociedade.

Como vimos, está em jogo, com as políticas de ação afirmativa, uma relação complexa de igualdade, que tenciona a tradição moderna baseada nos direitos individuais, ao propor uma redefinição da igualdade de oportunidades liberal, introduzir a utilização de particularidades grupais e ao dar uma ênfase positiva à construção de identidades raciais. No caso do Brasil, além desses embates no campo normativo, a utilização da raça para a definição de políticas confronta-se com a idéia de uma nação que se imagina miscigenada e indiferente às distinções raciais.

\section{A mestiçagem brasileira}

Observando o debate brasileiro atual sobre relaçôes raciais, percebe-se que o reconhecimento da existência de desigualdades entre grupos raciais no acesso a bens e serviços é objeto de razoável consenso. Vários estudos, como aqueles realizados pelo Instituto de Pesquisa Econômica Aplicada (IPEA), demonstram o quão profundas são as distâncias entre brancos e negros (pretos e pardos) em quase todas as esferas da vida social. Contudo, as explicações do porquê de tal situação e, prin- 
Ação afirmativa no ensino superior: entre a excelência e a justiça racial

cipalmente, as proposições de soluções adentram um terreno controverso. Não serão as condiçóes desfavoráveis da população negra, na verdade, conseqüência da pobreza em que vivem? E, sendo assim, não seria mais adequado adotar políticas universais em vez de políticas direcionadas a grupos raciais específicos? Afinal, existe racismo no Brasil? Há um problema especificamente racial no país?

As políticas de ação afirmativa tencionam não apenas os marcos da tradição liberal universalista e sua noção de igualdade e mérito, mas também nossa noção de povo mestiço convivendo sob uma harmonia racial, idéia com a qual o Brasil tem se identificado há anos. Casa-grande e senzala, de Gilberto Freyre, foi a obra que mais influenciou essa imagem positiva da mestiçagem brasileira, tida pelo autor como um símbolo per se de sociedade anti-racista. Como poderiam existir diferentes raças em um país tão densamente miscigenado? Em um momento de transição para a modernidade, industrialização e construção da nação que foram os anos de 1930, o passado escravista teria de ser superado em nome de um ideal de harmonia e democracia nas relaçôes entre os grupos étnicos.

Nos anos de 1950, os estudos desenvolvidos por Florestan Fernandes romperam com o paradigma culturalista anterior e inauguraram uma nova interpretação das relaçōes raciais brasileiras, com um enfoque mais estrutrural-funcionalista. Em $A$ integração do negro na sociedade de classes (1978 [1965]), Fernandes ressalta o racismo e as desigualdades raciais existentes no país e questiona nossa suposta democracia racial, redefinida como um mito, uma falsa realidade que, paradoxalmente, contribui para inviabilizar sua própria efetivação. Observa que, apesar do fim do sistema escravista, a ordem racial permaneceu intacta, estabelecendo-se "uma espécie de composição entre o passado e o presente, entre a sociedade de castas e a sociedade de classes" (Fernandes, 1978, p. 248). O antigo regime persistiria na mentalidade, no comportamento, na organização das relaçôes sociais e nas desigualdades entre brancos e negros. No entanto, imaginava que, com a intensificação da industrialização e das mudanças estruturais na sociedade brasileira, as injustiças raciais históricas seriam superadas.

Contrapondo-se, por sua vez, à perspectiva de Florestan Fernandes, as pesquisas realizadas por Carlos Hasenbalg e Nelson do Valle e Silva nos anos de 1980 mostraram a relevância da discriminação propriamente racial como um traço contemporâneo da sociedade brasileira. Mais que 
uma herança da escravidão, observam que as desigualdades socioeconômicas entre brancos e negros - ou não-brancos, como preferem decorrem da discriminação racial que se perpetua nas sociedades capitalistas. Compreendem o racismo como uma ideologia e um conjunto de práticas que re-elaboram as "sobrevivências" do antigo regime e as transformam dentro da nova estrutura social (cf. Hasenbalg, 1979, p. 76). A raça/cor é vista como um "esquema classificatório e um princípio de seleção racial que está na base da persistência e reprodução de desigualdades sociais e econômicas entre brasileiros brancos e não-brancos" (Hasenbalg \& Silva, 1992, p. 11).

Utilizando-se dos dados produzidos sobre desigualdades raciais e das distinções estabelecidas entre discriminação racial e socioeconômica, o movimento negro passou a denunciar a democracia racial e a mestiçagem brasileira como um etnocídio, na medida em que negavam ao negro uma existência própria. Entendeu-se que realçar as diferenças romperia com a lógica do racismo brasileiro e propiciaria ao negro um espaço positivo e valorizado na sociedade brasileira que antes lhe foi vedado. A afirmação de uma identidade negra, afrodescendente ou afro-brasileira, distinta da idéia do mestiço, caracterizou o anti-racismo diferencialista do movimento negro desde então (D’Adesky, 1996).

Contudo, a classificação bipolar defendida pelo movimento negro e a identificação racial exigida pelas políticas de ação afirmativa atentam, segundo alguns pesquisadores (Maggie \& Gonçalves, 1995; Maggie, 1996; Fry, 1996), contra a tradição brasileira e seu modo de pensar as relações raciais, baseadas num não-racismo universalista, fundado em valores modernos de respeito ao indivíduo que buscam integrar os diversos grupos étnicos e raciais. Numa posição inversa à assumida pelo movimento negro, ressaltam que nossa sociedade seria fundada por mitos raciais que evitaram realçar as diferenças entre os grupos e afirmam que tal postura encontraria pouca receptividade entre a população, além de abrir espaço para animosidades raciais então desconhecidas. Sem negar a existência de discriminação e desigualdades raciais no país, defendem que tomemos o mito da democracia racial como um ideal, como um conjunto de valores a orientar um projeto de não-racismo universalista propriamente brasileiro.

No Brasil, não haveria brancos, negros ou índios, apenas brasileiros. O sistema de classificação racial e o discurso das pessoas comuns teriam um "intrincado modo de falar muito de cor sem falar de oposi- 
Ação afirmativa no ensino superior: entre a excelência e a justiça racial

ção" (Maggie, 1996, p. 233). O racismo e a hierarquia entre as raças, no imaginário brasileiro, seriam como que uma antítese do que é "ser brasileiro", ou seja, faria parte de nossa identidade a oposição ao racismo e às diferenças raciais:

O modelo brasileiro de representar a diferença suprimindo-a, colocando-a num passado, gera um sistema obsessiva e essencialmente anti-racista. Onde ser racista é considerado um pecado capital que ameaça e põe em cheque o mito de origem da sociedade brasileira e atenta contra a identidade nacional. (Maggie \& Gonçalves, 1995, p. 4)

Apesar de reconhecerem que nossa ideologia da democracia racial reduz as desigualdades a uma questão de classe social, negando existir um problema especificamente racial, na visão de Maggie, Gonçalves e Fry os valores e o ideal de sociedade por essa ideologia difundidos deveriam ser preservados, pois teriam forte apelo no imaginário social brasileiro e poderiam contribuir para a construção de uma sociedade menos desigual. Opõem-se à afirmação de identidades raciais, que acusam de uma essencialização racial. Entendem que o negro, o branco e o índio e suas particularidades não apenas estão, mas também devem permanecer no passado.

A posição desses pesquisadores sustenta que a utilização e a difusão de diferenciações em termos raciais podem levar a uma armadilha, favorecendo antes ao racismo e à discriminação que à igualdade e à harmonia entre os grupos raciais. No entanto, relativizam as próprias ciladas do projeto não-racista que defendem. Reforçar a democracia racial, mesmo que na condição de ideal de sociedade, não implicaria o risco de apenas perpetuar nossa maneira "nativa" de discriminar e inferiorizar determinados grupos raciais, ainda que de modo sutil, sem que qualquer questão de raça precise ser nomeada? Como escolher entre as "ciladas da diferença” e as ciladas da democracia racial? Em qual apostar nossas fichas?

Para Antônio Sérgio Guimarães, a identificação e a utilização de critérios raciais tornam-se necessários diante da maneira como opera o racismo na sociedade brasileira. Polarizando com a visão de Yvonne Maggie e Peter Fry, entende que a raça, ainda que não exista biologicamente, tem uma presença nominal no mundo social. Durante anos não fez parte de nossos discursos cotidianos, mas nem por isso as desi- 
gualdades entre grupos sociais diminuíram. Sustenta o uso público do termo "raça" como uma estratégia anti-racista. Concebe-o não apenas como

uma categoria política necessária para organizar a resistência ao racismo no Brasil, mas é também categoria analítica indispensável: a única que revela que as discriminações e desigualdades que a noção brasileira de "cor" enseja são efetivamente raciais e não apenas de "classe". (Guimarães, 2002, p. 50)

Ao reivindicar o uso do termo "raça", sujeito no Brasil a constantes transformações e disfarces sob diferentes formas, Guimarães procura explicitar a permanente associação entre raça, cor e posição social. Para tanto, desenvolve a idéia do Brasil como uma "sociedade de status":

(...) sociedade onde os grupos sociais, inclusive as classes sociais, desenvolveram "direitos" a certos privilégios em relação ao Estado e aos outros grupos sociais. Tais privilégios de posição são resguardados, no plano das relaçōes entre sujeitos, por distâncias e etiquetas, que têm na aparência e na cor, (...) suas principais referências e marcos no espaço social. (Guimarães, 1997, p. 169)

A sociedade de classes no Brasil não suporia uma ordem social igualitária e relações sociais abertas. Recorrendo a Roberto Da Matta, Guimarães irá afirmar que as peculiaridades de nosso racismo se relacionam à estrutura profundamente hierarquizada da sociedade brasileira, onde cada um tem um lugar definido:

Aqui, o senhor não se sente ameaçado ou culpado por estar submetendo um outro homem ao trabalho escravo, mas, muito pelo contrário, ele vê o negro como seu complemento natural, como um outro que se dedica ao trabalho duro, mas complementar às suas próprias atividades que são as do espírito. Assim a lógica do sistema de relações sociais no Brasil é a de que pode haver intimidade entre senhores e escravos, superiores e inferiores, porque o mundo está realmente hierarquizado, tal e qual o céu da Igreja Católica. (Da Matta, 1993, p. 75)

Nesse sistema, no qual ninguém é igual nem entre si nem perante a lei e as hierarquias são rígidas, não houve a necessidade de segregar o negro. Nossa democracia racial e a idéia de relações raciais harmônicas só foram possíveis em razão da ausência de valores e relações sociais efetivamente igualitários no país. Desse modo, o uso do termo "raça" e a explicitação das distinções raciais vigentes, como fazem as políticas de ação 
Ação afirmativa no ensino superior: entre a excelência e a justiça racial

afirmativa, seriam uma maneira de desmascarar o racismo, como também de questionar a ausência de igualdade e a naturalização das hierarquias sociais brasileiras.

Como apenas iniciamos no país experiências com ação afirmativa, seria difícil prever se os receios levantados quanto à utilização da raça se concretizariam. $\mathrm{O}$ que podemos analisar, por intermédio das experiências de outros países, como os Estados Unidos, seria seu potencial de transformar as desigualdades raciais e as dificuldades que apareceram ao longo desse processo.

\section{A experiência norte-americana no ensino superior}

O que podemos dizer sobre o impacto das políticas de ação afirmativa nas oportunidades de acesso ao ensino superior nos Estados Unidos nos últimos 40 anos? A ação afirmativa, como política voltada para a melhoria da igualdade entre os grupos raciais, funcionou? Políticas racialmente neutras alcançariam o mesmo resultado?

Durante o período de 1960 a 2000, os dados ${ }^{1}$ levantados mostram um quadro positivo, com um aumento significativo da população negra ingressante na educação superior. A porcentagem de negros na idade ideal $^{2}$ matriculada passou de $13 \%$ em 1967 para 30,3\% em 2000, sendo o momento de maior crescimento de 1967 a 1976, quando praticamente dobrou a porcentagem daqueles ingressantes. De 1961 a 1966, antes da difusão de programas de ação afirmativa, o número de negros no ensino superior permaneceu praticamente o mesmo: eram 233 mil em 1961 e 221 mil em 1966. A população negra matriculada no ensino superior representava 4,4\% do total em 1966; dez anos depois, o número de negros sobe para 1 milhão e 33 mil e sua proporção, para 9,6\%.

Contudo, não podemos atribuir esses resultados exclusivamente às políticas de ação afirmativa. Ao contrário do que muitos imaginam, a utilização de políticas sensíveis à raça nos processos de admissão restringiu-se basicamente a universidades seletivas, que representam de 20 a 30\% do total das instituições de ensino superior dos Estados Unidos (Kane, 1998). Quando da pressão pela implementação de programas de ação afirmativa, essas universidades se vêem diante do desafio de incorporar efetivamente ideais de igualdade social e racial aos valores de 
excelência acadêmica no acesso à educação superior. Para entender um pouco as modificações pelas quais passaram essas universidades, analisamos a Universidade da Califórnia (UC), uma instituição altamente seletiva, pública e de pesquisa, que nos anos de 1960 foi pioneira na utilização de programas de ação afirmativa e nos anos de 1990 foi a primeira a abolir a utilização da raça nos seus processos seletivos.

\section{A Universidade da Califórnia}

Antes de 1960, existiam duas principais formas de acesso aos campi da UC: a) as admissóes regulares, nas quais eram exigidas dos novos ingressantes notas superiores a uma média específica nos cursos realizados no ensino médio; b) e as admissões especiais, nas quais eram avaliadas as situações de desvantagem, talentos e circunstâncias especiais dos candidatos. Uma terceira forma de ingresso era a transferência de alunos oriundos dos Junior colleges que alcançassem nota $A$ em certas disciplinas. As admissóes especiais surgiram como uma resposta da universidade às enormes diferenças na qualidade e no financiamento das escolas de ensino médio do estado.

Em 1960, diante do dramático crescimento de candidatos e demanda por vagas, decidiu-se que a UC deveria selecionar seus novos ingressantes dentre os que estivessem entre os $12,5 \%$ melhores de sua classe no ensino médio. Previu-se, ainda, a adoção de um teste nacional padronizado, o Scholastic Assesment Test (SAT). Mas, como contrapeso a esse aumento da importância dos testes, foram criados programas de ação afirmativa para garantir uma igualdade nas oportunidades de acesso à universidade. As primeiras pesquisas sobre rendimento familiar e etnia de estudantes da UC, realizadas após a aprovação do Civil Rights Act de 1964, mostraram significativas e crescentes disparidades entre a população do estado e os estudantes da universidade. Reforçou-se nesse momento a visão de que a UC, por ser uma instituição pública, teria o compromisso e a obrigação sociais de promover oportunidades educacionais viáveis a todos os estudantes em condições de freqüentá-la e que seus alunos deveriam refletir a composição étnica, racial e de gênero dos estudantes de ensino médio formados no estado (Douglass, 1997).

Entretanto, em 1977, como resultado de queixas contra uma perda na qualidade da instituição, aumentou-se a exigência acadêmica em 
Ação afirmativa no ensino superior: entre a excelência e a justiça racial

testes ao combinar a nota no SAT com aquelas obtidas no ensino médio, diminuindo o peso atribuído às dificuldades econômicas e raciais enfrentadas pelos estudantes. Tais mudanças refletiram o clima e as polêmicas criados em torno do caso Bakke, julgado pela Suprema Corte norte-americana em 1978, e que seria um marco na definição daquilo que é ou não permitido nos programas de ação afirmativa adotados por instituições de ensino superior. Allan Bakke abriu um processo contra a UC em Davis, alegando que a faculdade de medicina o discriminou por ser branco ao adotar sistemas de admissão distintos, um para brancos e outro para não-brancos, e negou-lhe admissão ao mesmo tempo em que aceitou estudantes negros com notas inferiores às suas. A Suprema Corte, com um resultado de cinco votos favoráveis e quatro contrários, decidiu que o sistema de ingresso utilizado, baseado em cotas rígidas, era ilegal, mas definiu como legítimo a utilização da raça como critério na seleção de alunos desde que combinado com outros. O programa utilizado pela Universidade de Harvard, no qual as características raciais e socioeconômicas dos candidatos são quantificadas e computadas às demais notas obtidas como forma de equalização das oportunidades, foi citado como um dos modelos aceitáveis de ação afirmativa.

Justifica-se que a raça poderia ser utilizada como critério de ingresso desde que isso ocorresse para reparar uma situação de desvantagem que atingisse determinado grupo em conseqüência da discriminação racial passada e presente. $\mathrm{Ou}$, ainda, que a raça seria um meio de garantir a diversidade no interior das instituiçôes de ensino superior, já que a convivência entre diferentes grupos étnicos enriqueceria essa experiência e seria parte dos objetivos da educação.

Em 1979, o reitor da UC, após a decisão do caso Bakke, informou que raça/etnia poderiam ser utilizadas nos processos regulares de admissão. Explicou ele:

Notas e testes sozinhos (...) não necessariamente prevêem de forma acurada o potencial para completar um programa de forma satisfatória. (...) Em razão de barreiras e obstáculos freqüentemente associados a raça, sexo e deficiências físicas, (...) o status de ser membro de tais grupos subrepresentados pode ser considerado um indicativo da necessidade de um escrutínio especial para determinar se o registro reflete de forma apropriada o potencial acadêmico do candidato. (University of California Guidelines, 1979, p. 8) 
Em 1995, a Universidade da Califórnia iniciou uma revisão de seu programa de ação afirmativa, concluída com a aprovação da SP 1 e SP 2 pelo Conselho de Regentes. Essas resoluções proibiram que a instituiçãao utilizasse raça, religião, sexo, cor, etnia ou origem nacional como critério para a admissão regular ou por exceção de estudantes, ou na seleção de empregos e contratos. Foi-lhe permitido ter apenas uma consideração especial com indivíduos que, apesar de terem sofrido desvantagens socioeconômicas, demonstrassem perseverança e capacidade de acompanhar os estudos na instituição. A UC tornou-se a primeira universidade a abolir a utilização da raça como um de seus critérios de seleção; contudo, ao contrário do que se pode pensar, mantiveram-se os programas de ação afirmativa.

Num primeiro momento, as novas ações de inclusão racialmente neutras tiveram como estratégia a busca de maior aproximação com as escolas de ensino médio, com atividades de recrutamento e formação, realizadas por intermédio de seleção e avaliação dos alunos baseadas em critérios socioeconômicos. Entretanto, os resultados alcançados por esses programas não foram animadores. Até 2000, os alunos negros continuavam sub-representados em níveis muito inferiores aos de 1997. Com o fim da utilização de critérios raciais, a porcentagem de alunos negros retornou àquela dos anos de 1960 .

Apenas em 2001, depois de realizar novas alteraçôes no sistema de ingresso, a UC conseguiu melhorar essa representação do seu corpo discente. Nesse ano, passaram a utilizar o modelo de admissão originário do Estado do Texas, o Plano dos 10\% Melhores. De acordo com esse Plano, todos os estudantes de escolas do ensino médio do Estado do Texas que estiverem entre os $10 \%$ melhores alunos de sua classe no último ano de curso e se candidatarem a uma vaga nas universidades do estado serão automaticamente aceitos. Com um plano semelhante, a UC conseguiu elevar o número de estudantes negros admitidos, contudo esse processo de seleção levou a uma hierarquia entre os campi e os cursos da instituição, pois, ao contrário do ocorrido no Texas, na UC os estudantes nem sempre ingressavam em sua primeira opção de curso. Como consequiência, a representação de alunos negros cresceu apenas nos campi e nos cursos menos concorridos.

O que vale observar das mudanças pelas quais a UC passou ao longo desse processo é que, mesmo após os reveses e a extinção de medi- 
Ação afirmativa no ensino superior: entre a excelência e a justiça racial

das raciais, a preocupação com a igualdade e a diversidade de seus campi continua parte dos objetivos básicos da instituição, refletidos em seu lema: Access through quality, and quality through access. $\mathrm{O}$ que se define hoje como uma universidade de excelência nos Estados Unidos, diferentemente do que ocorria até os anos de 1960, envolve necessariamente valores como a inclusão, igualdade e diversidade.

\section{A seleção e a responsabilidade social da universidade}

Tanto no Brasil quanto nos Estados Unidos, uma das principais polêmicas com relação às políticas de ação afirmativa envolve a escolha de ações class-based ou race-based, que refletem distintas concepções de igualdade, universalistas ou particularistas, e diferentes interpretações sobre as relações raciais e a pertinência da utilização da raça como critério de seleção. Em termos práticos, podemos imaginar que, como a maioria da população negra, tanto norte-americana quanto brasileira, vive na pobreza, políticas sociais racialmente neutras resolveriam o problema. As experiências analisadas, porém, não nos permitem afirmar que apenas políticas sociais seriam suficientes para resolver uma situação de desigualdade racial que perdura há anos em ambos os países. Isso porque, além da discriminação social, a população negra enfrenta também a discriminação racial, ou seja, existe nesse caso uma situação de dupla discriminação. Ao invés de excludentes, essas são medidas, na verdade, complementares. A utilização de políticas de ação afirmativa no ensino superior brasileiro, por exemplo, não poderá prescindir da expansão e melhoria na qualidade da educação básica. Considerando ainda o modo intrincado com que raça e classe se relacionam no Brasil, a extensão da igualdade almejada dependerá, em muito, da capacidade de combinarmos políticas sociais e raciais.

No caso da educação superior, a opção por critérios sociais ou raciais tangencia ainda outra polêmica: a questão do mérito e da qualidade. Com relação às tensões e acomodações em torno da defesa da qualidade e da igualdade como valores essenciais de uma universidade de excelência, as medidas utilizadas pela UC ao longo das últimas décadas evidenciaram que não só é possível conciliá-los como também eles se tornaram indissociáveis e impregnam de sentido aquilo que é a instituição hoje. Certamente houve críticas e preocupações quanto à queda na qualidade de seus cursos, mas estas foram respondidas com me- 
didas equilibradas na seleção dos alunos e nos programas de acompanhamento nos cursos, fazendo com que a UC se mantivesse sempre entre as melhores universidades do país. A Universidade do Texas, em Austin, também percebeu que admitir alunos com notas abaixo da média em testes padronizados como o SAT não prejudicou seu desempenho nos cursos nem diminuiu a imagem da instituição perante a comunidade. Chegou a observar, antes, que os estudantes admitidos pelo Plano dos $10 \%$ até superaram seus colegas.

Para além da questão do desempenho, estudos realizados desde os anos de 1970 nos Estados Unidos já mostravam que estudantes negros possuíam, quando em universidades seletivas, menores taxas de evasão (Austin, 1970), maiores taxas de conclusão de estudos (Kane, 1998; Karabel, 1998) e ganhos salariais futuros equivalentes aos de seus colegas brancos (Kane, 1998). Ou seja, quando consideramos as instituições que utilizam preferências raciais na seleção dos candidatos, em geral as mais concorridas, o impacto sobre estudantes negros é melhor que nas demais. Esses estudos indicam que as políticas de ação afirmativa têm beneficiado os alunos negros, e não o inverso.

Como afirmou o reitor da Universidade da Califórnia em 1979, avaliar por meio de testes padronizados a capacidade acadêmica de candidatos cuja trajetória educacional é caracterizada pela superação de adversidades que suas condiçôes de vida lhes impuseram nem sempre é a medida mais adequada nem a que melhor prediz o desempenho desses candidatos nos cursos superiores. Esses que chegam às portas do ensino superior trazem consigo a marca da persistência e perseverança diante das "profecias que se auto-realizam" encontradas ao longo da vida, um traço de caráter importante e necessário àqueles que desejam enfrentar um curso superior.

Universidades como a da Califórnia e a do Texas em Austin redefiniram sua concepção de mérito, tornando-a mais inclusiva, à medida que contemplaram na escolha de candidatos a avaliação da capacidade de superar dificuldades e obstáculos que encontraram na vida, o que teria demandado desses candidatos um esforço maior que aquele dispensado por outros que experimentaram condições mais favoráveis. Balanços preliminares realizados pela Universidade Estadual da Bahia (UNEB) e pela Universidade Estadual do Rio de Janeiro (UERJ) no início de 2004 mostram que essa escolha pode trazer resultados positivos semelhantes no Brasil. Na UERJ, por exemplo, 49\% dos alunos ingressan- 
Ação afirmativa no ensino superior: entre a excelência e a justiça racial

tes pelo sistema de cotas teriam passado de ano sem nenhuma dependência, contra $47 \%$ dos alunos escolhidos pelo sistema vestibular. A evasão entre os alunos negros, no primeiro ano, foi de $5 \%$ e entre os demais alunos, de $9 \%$. Na UNEB, a evasão entre os alunos negros também foi menor: $1,9 \%$ contra 2,7\% (Souza, 2004).

Discute-se hoje, nos vários projetos de reforma para o ensino superior brasileiro, a importância do compromisso social das instituiçóes de ensino superior e a redefinição de mecanismos de acesso e permanência com o objetivo de garantir a estas um caráter mais inclusivo e eqüitativo. A preocupação com os estudantes oriundos de escolas públicas, negros e indígenas está contemplada nas propostas, assim como a possibilidade de utilização de políticas de ação afirmativa e o sistema de cotas. Contudo, para podermos avançar nesse debate, faz-se necessário, antes, incorporarmos uma redefinição também inclusiva do que as instituições estão entendendo por mérito, ou seja, que em vez de oporem maior igualdade no acesso à continuidade da qualidade oferecida tomem-na como parte desta. $\mathrm{O}$ mérito passaria a significar, então, a capacidade que os estudantes têm de, em condições adversas, superarem as dificuldades encontradas por meio do esforço realizado, mesmo que os resultados ainda não sejam os mesmos que os daqueles estudantes que se encontravam em situaçōes bem mais favoráveis. O mérito concebido com medida justa do empenho de cada um. Para além de uma mera retórica, essa concepção tem se mostrado não só necessária, diante das desigualdades de oportunidades de acesso existentes, mas também viável, como indicam os resultados positivos alcançados pelas instituições que utilizaram programas de ação afirmativa.

Recebido e aprovado em setembro de 2004.

\section{Notas}

1. As fontes de dados utilizadas foram o U.S. Census Bureau e o National Center for Educational Statistics.

2. São considerados na idade ideal para o ensino superior aqueles entre 18 e 25 anos.

\section{Referências bibliográficas}

AUSTIN, A.W. Racial considerations in admissions. In: Nichols, D.; Mills, O. (Ed.). The campus and the racial crisis. Washington: ACE, 1970. 
BOBBIO, N. Dicionário de política. 5. ed. Brasília: Editora da UnB, 1993. BOBBIO, N. Igualdade e liberdade. 2. ed. Rio de Janeiro: Ediouro, 1997. CHAVES, M. Aviltante discriminação racial. O Estado de S. Paulo, São Paulo, 15 dez. 2001.

D'ADESKY, J. Pluralismo étnico e multiculturalismo: racismo e anti-racismos no Brasil. 1996. Tese (doutorado) - Faculdade de Filosofia, Letras e Ciências Humanas. Universidade de São Paulo, São Paulo.

DA MATTA, R. Digressão: a fábula das três raças, ou o problema do racismo à brasileira. In: Relativizando: uma introdução à antropologia social. 4. ed. Petrópolis: Vozes, 1993 [1981].

DOUGLASS, J.A. A short history of UC admissions. Document for California State Senate Select Committee on Higher Education Admissions and Outreach. September 1997.

FERNANDES, F. A integração do negro na sociedade de classes. São Paulo: Companhia Editora Nacional, 1978 [1965].

FRY, P. O que a Cinderela negra tem a dizer sobre a "política racial" no Brasil. Revista USP, Dossiê Povo Negro - 300 Anos, São Paulo, n. 28, dez./fev. 1996. p. 122-135.

GUIMARÃES, A.S.A. A desigualdade que anula a desigualdade: notas sobre a ação afirmativa no Brasil. In: SouZA, J. (Org.). Multiculturalismo e racismo: uma comparação Brasil-Estados Unidos. Brasília: Paralelo 15, 1997. p. 233-242.

GUIMARÃES, A.S.A. Classes, raças e democracia. São Paulo: Editora 34, 2002.

HASENBALG, C.A. Discriminaçôes e desigualdades raciais no Brasil. Rio de Janeiro: Graal, 1979.

HASENBALG, C.A.; SILVA, N.V. Relaçōes raciais no Brasil contemporâneo. Rio de Janeiro: Rio Fundo, 1992.

KANE, T.J. Misconceptions in the debate over affirmative action in college admissions. In: Orfield, G.; Miller, E. (Org.). Chilling admissions: the affirmative action crisis and the search for alternatives. Cambridge: The Civil Rights Project/Harvard University/Harvard Education Pub. Group, 1998. p. 17-32. 
Ação afirmativa no ensino superior: entre a excelência e a justiça racial

KARABEL, J. No alternative: the effects of color-blind admissions in California. In: Orfield, G.; Miller, E. (Org.). Chilling admissions: the affirmative action crisis and the search for alternatives. Cambridge: The Civil Rights Project/Harvard University/Harvard Education Pub. Group, 1998. p. 33-50.

KYMLICKA, W. Contemporary political philosophy: an introduction. Oxford: Clarendon Press, 1996.

MAGGIE, Y. Aqueles a quem foi negada a cor do dia: as categorias cor e raça na cultura brasileira. In: MAIO, M.C.; SAnTOS, R.V. (Org.). Raça, ciência e sociedade. Rio de Janeiro: FIOCRUZ/CCBB, 1996. p. 225-234.

MAGGIE, Y.; GONÇALVES, M.A. Pessoas fora do lugar: a produção da diferença no Brasil. In: Gonçalves, M.A.; Villas Boas, G. (Org.). $O$ Brasil na virada do século. Rio de Janeiro: Relume-Dumará, 1995.

MOEHLECKE, S. Propostas de açôes afirmativas no Brasil: o acesso da população negra ao ensino superior. 2000. Dissertação (mestrado) Faculdade de Educação. Universidade de São Paulo, São Paulo.

MUNANGA, K. Rediscutindo a mestiçagem no Brasil. Rio de Janeiro, Petrópolis: Vozes, 1999.

PRESIDENTE do Supremo defende cotas para negros. Correio Brasiliense, Brasília, 6 set. 2001.

RAWLS, J. A theory of justice. Cambridge, MA: Harvard University Press, 1973.

RAWLS, J. Uma teoria da justiça. 2. ed. São Paulo: Martins Fontes, 2002. SANTOS, J.T. Dilemas nada atuais das políticas para os afro-brasileiros: ação afirmativa no Brasil dos anos 60. In: Bacelar, J.; Caroso, C. (Org.). Brasil, um pais de negros? Rio de Janeiro: Pallas; Salvador: CEAO, 1999. p. 221-234.

SOUZA, M. Cota leva mais de sete mil negros à universidade $O$ Estado de S. Paulo, São Paulo, 28 jan. 2004.

UNIVERSITY of California guidelines on fair and equal opportunities to participate in undergraduate and graduate programs. University of California/President David Saxon, 12 jun. 1979. 